\title{
Schwannoma of the 6th nerve: case report and review of the literature
}

\author{
Xin $\mathrm{Li}^{1}$, Jingjun $\mathrm{Li}^{2}$, Jing $\mathrm{Li}^{3}$ and Zhen $\mathrm{Wu}^{{ }^{*}}$
}

\begin{abstract}
Introduction: Schwannomas of the 6th nerve are extremely rare.Only 22 cases of intracranial schwannomas of the 6th cranial nerve pathologically confirmed have been reported.

Case Presentation: Here, we report a case of a 14-year-old girl who presented with isolated progressive 6th nerve palsy. A cisternal type of schwannomawas found from neuro-imaging. Subtotal removal of the tumor was performed by a routine left subtemporal craniotomy with an petrosectomy. The attachment to the 6th nerve was found. After surgery, the patient's 6th nerve palsy remained. Histological images revealed a cellular schwannoma. Then the classification, clinical presentation, diagnosis, operation, stereotactic radiosurgery are reviewed.

Conclusions: The location and the attachment to the 6th nerve is the key for diagnosis. Most cases are treated surgically. It looks like it is not easy to completely remove for CA type because of invasion of the cavernous sinus or firm adherence to the nerves. The 6th nerve function seldom completely recovered postoperatively. The direction of further research is to improve the diagnosis and therapy to have better nerve recovery.
\end{abstract}

Keywords: Schwannoma; Abducens nerve; 6th nerve palsy; Tumor

\section{Background}

Intracranial schwannomas, one of the frequent intracranial tumors, originate from the sensory nerve, such as vestibular or less commonly from the trigeminal nerve, with the exception of optic and olfactory nerves. The pure motor nerves (3rd, 4th, and 6th) are rarely affected by schwannomas [1]. Schwannomas of the 6th nerve are extremely rare. To date, only 22 cases have been reported of intracranial schwannomas of the 6th cranial nerve pathologically confirmed. Here, we report a case of a 14-year-old girl who presented with an isolated progressive 6th nerve palsy and was found to have a cisternal type of schwannoma.

\section{Case report}

\section{History and examination}

A 14-year-old girl presented with a 3-year history of diplopia. She developed an isolated 6th nerve palsy with no

\footnotetext{
*Correspondence: wuzhen1966@aliyun.com

'Department of Neurosurgery, Beijing Tian Tan Hospital, Capital Medical

University, China National Clinical Research Center for Neurological Diseases, Center of Brain Tumor, Beijing Institute for Brain Disorders, Beijing Key Laboratory of Brain Tumor, Beijing, China

Full list of author information is available at the end of the article
}

nausea, vomiting, or headache. Neurologic examination revealed normal except the left 6th nerve palsy. A review of her pictures revealed a mild 6th nerve palsy at 10 and 12 years old (Fig. 1a, b) that was progressing (Fig. 1c). She had been scheduled for orthopedic eye surgery at Beijing Tongren Hospital when a small intracranial mass in the prepontine cistern was found by an MRI scan.

\section{Neuroimaging}

A series of four scans provided further information about the tumor. Coronal T1-weighted MRI (Fig. 2a) showed a hypo-intense clear-boundary solid tumor with intratumoral cysts and with a maximum diameter of about $1.2 \mathrm{~cm}$. Axial T2-weighted MRI (Fig. 2b) showed a hyper-intense solid tumor. The tumor was strongly enhanced on coronal (Fig. 2c) and axial T1-weighted (Fig. 2d) MRI and had no relation with the dura. A CT (Fig. 2e) revealed a mild hyper-density mass in the prepontine area.

\section{Operation}

A routine left subtemporal craniotomy with a petrosectomy was performed. First, the tentorium of the cerebellum was partially incised and then petrosectomy was

\section{实 Springer}




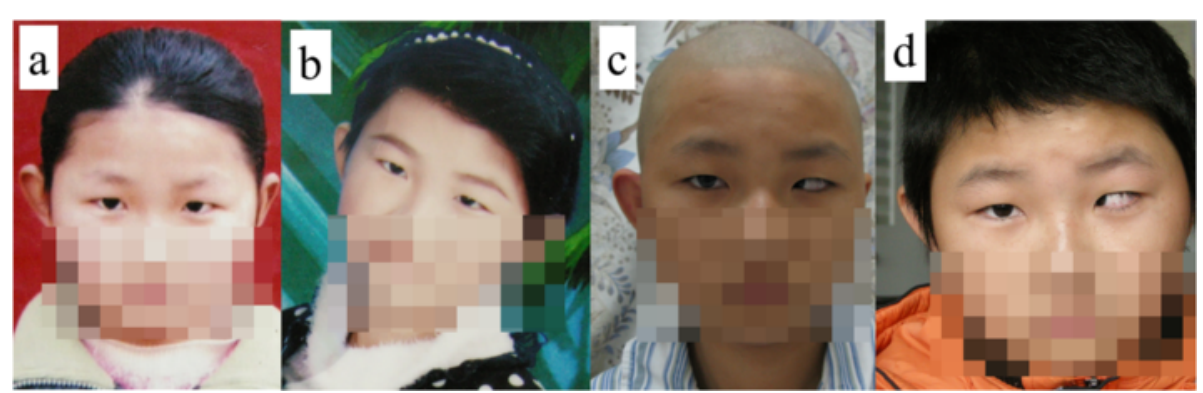

Fig. 1 Preoperative and postoperative images reviewed her left 6th nerve palsy development process at different periods. a The 10-year-old photograph showed her left eye was located in mild adduction. b The 12-year-old photograph showed her left esotropia development. c The 14-year-old photograph showed her left esotropia obviously. The development process is gradually increased. d The 17-year-old photograph, 3 years postoperative, displayed her left abducens nerve paresis and diplopia were unchanged

performed (Fig. 3a). It was gently dissected away from the surrounding structures and the brainstem (Fig. 3b). The tumor was located between the trigeminal nerve and the basilar artery and was encapsulated, slightly soft, without hemorrhage. The tumor had no relationship with the dura but was strongly adherent to the prepontine cisternal part of the 6th nerve, the pons, and the basilar artery (Fig. 3c). A subtotal removal was performed, leaving a residual slice of the tumor in the pons to avoid function loss of the brainstem (Fig. 3d). The slice was fulgurized to inactivate the tumor cells.

\section{Histopathology}

Histological images revealed a cellular schwannoma with spindle cells in a collagenous background (Fig. 4a, b). Cellular schwannomas are a variant of standard schwannomas [2]. The cells were densely distributed in most of the regions, showing a plexiform hyperplasia. The chromatin of the nucleus increased, the nucleus has moderate atypia, but nuclear division number is less, $<4 / 10$ HPF. A negative immunohistochemical staining for CD34 eliminated a diagnosis of hemangiopericytoma (Fig. 4c). Immunohistochemistry revealed diffuse strong
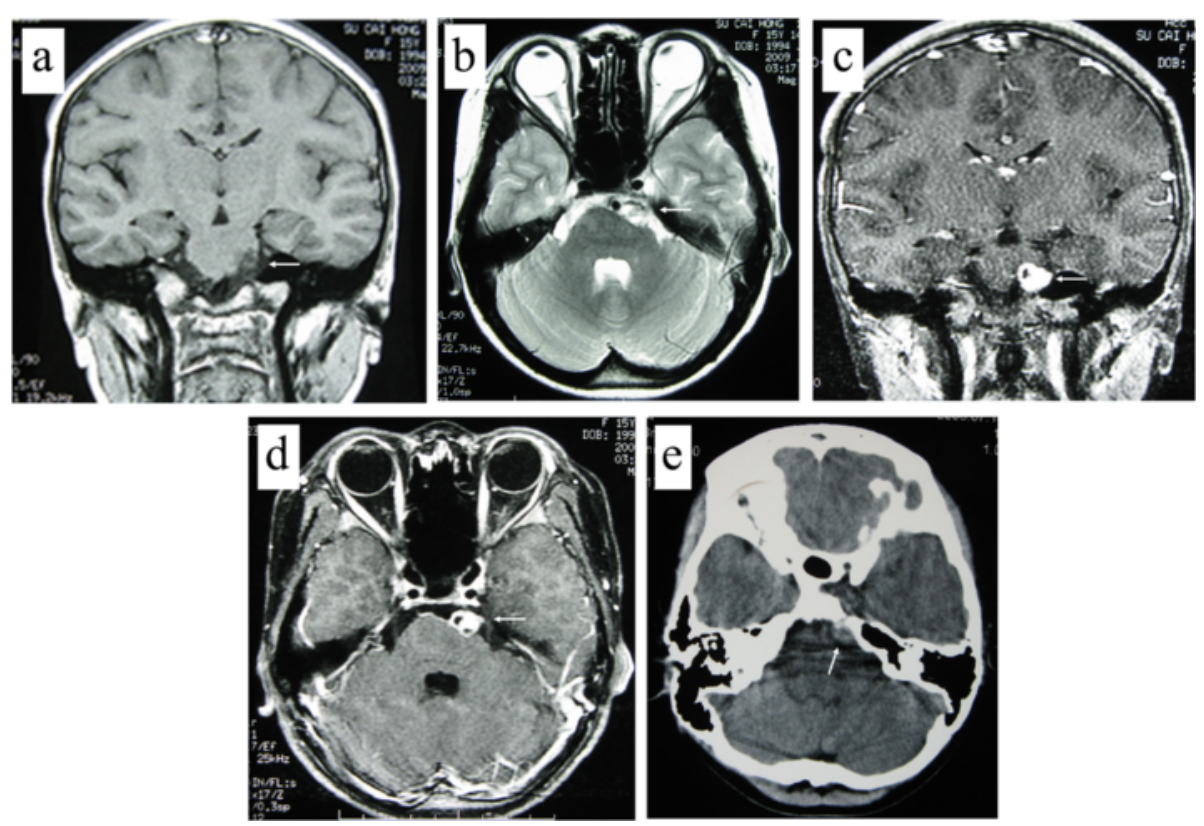

Fig. 2 Preoperative MRI and CT findings. a Coronal T1-weighted MRI represents a hypo-intense clear-boundary solid tumor (arrow) with intratumoral cysts and with a maximum diameter of about $1.2 \mathrm{~cm}$. b Axial T2-weighted MRI showed a hyper-intense solid tumor (arrow). c, $\mathbf{d}$ The tumor (arrow) strongly enhances heterogeneously with gadolinium on coronal and axial T1-weighted MRI and had no relation with the dura. e CT revealed a lighted hyper-density mass (arrow) in the prepontine area 


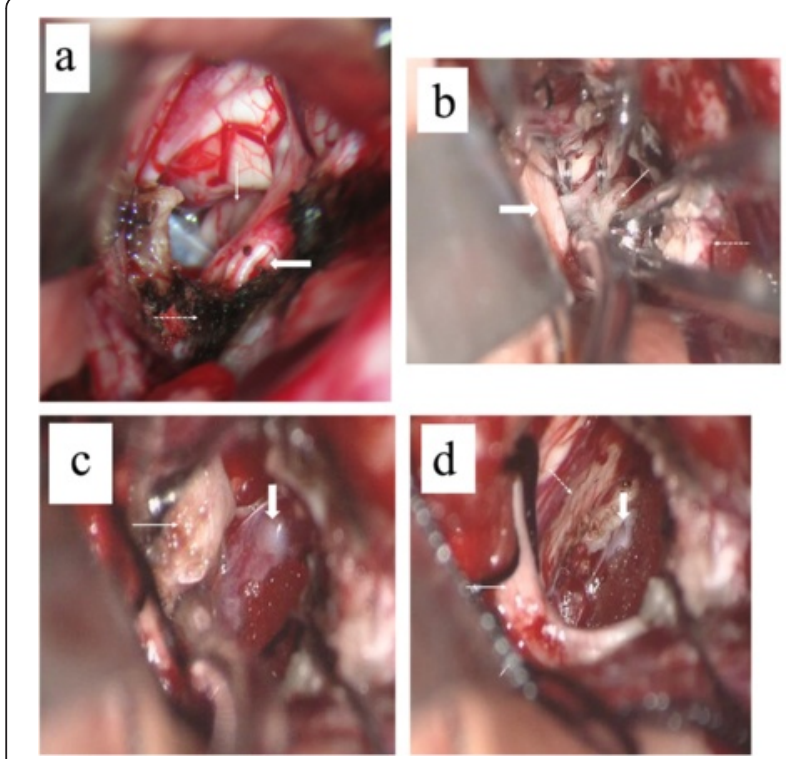

Fig. 3 Intraoperative photomicrograph. a The trigeminal nerve (thick arrow) and the tumor (thin arrow) are seen under the tentorium of the cerebellum (dashed line arrow), respectively. b Ampliative Dorello's canal (dashed line arrow) was stripped to expose the tumor (thin arrow) which was located under the trigeminal nerve (thick arrow). c The tumor (thin arrow) was located between the trigeminal nerve and the basilar artery (thick arrow). The tumor had no relationship with the dura but was strongly adherent to the pons and the basilar artery. $\mathbf{d}$ A subtotal removal was performed, and the trigeminal nerve (thin arrow), the pons (dashed line arrow), and the basilar artery (thick arrow) were seen

and uniform reactivity for S-100 protein in high-power fields which confirmed the diagnosis of schwannoma (Fig. 4d). The CK18 and EMA stains were negative. The Ki-67 proliferation index was $8 \%$.

\section{Postoperative course}

The postoperative course was uneventful. A MRI done on the 6th postoperative day showed decompression and revealed no residual tumor growth at the pons (Fig. 5a, b). Despite an excellent recovery from surgery, the 6th nerve palsy remained. The patient was not treated with followup radiation, because the histopathology was schwannoma (WHO I). Three months after the resection, MRI enhanced imaging revealed no recurrence of the tumor. One year after surgery, the MRI showed no enhancement of the mass compared to the prior scan. Three years after surgery, the patient's left abducens nerve paresis and diplopia were unchanged (Fig. 1d). The 5-year-control MRI scan revealed no evidence of the tumor.

\section{Discussion}

Intracranial schwannomas account for 6-8 \% of all primary brain tumors as a kind of benign tumor [1, 3]. They most commonly arise from the vestibular cranial nerves followed by the trigeminal nerve, facial nerve, and lower cranial nerves; they rarely affect pure motor CN (3rd, 4th, 6th) [1]. Schwannomas of the 6th cranial nerve are exceptionally rare. In the English literature, 22 cases have been reported of intracranial schwannomas of the 6th cranial nerve pathologically confirmed [4-23] (Table 1), except 4 cases reported by Hayashi et al. [24] who performed only stereotactic radiosurgery. We report a patient with a small schwannoma of the abducens nerve performed by surgical treatment based on a review of the literature.

\section{Classification}

According to the site where the schwannoma arises and its predominant location along the course of the 6th nerve, Tung [8] and Celli [25] have proposed two kinds of classification. Celli [25] divided the tumor into three types concerned for the 3rd to the 5th nerve: type I (cisternal, CI), 8 cases [4, 11-14, 17, 21] (present case) out of 22; type II (cavernous, CA), 5 cases [9, 10, 15, 18, 19] out of 22; and type III (cisternocavernous, CI-CA), 8 cases [5-8, 16, 20, 22, 23] out of 22. Tung [8] classified them into only two types: type I, schwannoma arises from the cavernous sinus, including the symptoms of the 6th nerve palsy and with or without mild headache; and type II, the tumor located in the prepontine area and perhaps accompanied by obstructive hydrocephalus, raised intracranial pressure, the 6th nerve palsy, and with or without other cranial nerve palsy. By contrast, Celli's classification which emphasizes on the anatomical position, without symptomatology, is more accurate and simple. But Tung's classification seems to be more comprehensive and stresses on symptomatology. The big tumors belonging to the CI-CA type of Celli's classification are difficult to be labeled using Tung's classification. Maybe it is only classified on the basis of the principal part or origination of the tumor using Tung's system.

\section{Clinical presentation}

It reveals an average age of 43.41 years old, from 10 to 68 years old. Eighteen out of 22 cases were over 30 years old ( $82 \%)$ and only 2 cases [5] (present case) were under 14 years old $(0.09 \%)$. The male/female ratio is about $1: 1$. A typical 6th nerve palsy was present in all except 3 of the reported patients $[17,21,23]$. Six cases $[6,8,16,22]$ (present case) presented isolated 6th nerve palsy. This indicates that a patient presenting an isolated 6th nerve palsy, with a specific mass in CI or CA found in neuroimaging, could be likely to diagnose a schwannoma of the 6th cranial nerve preliminarily. Twelve cases included signs of other cranial nerves, 9 cases [5, 7, 9-14, 18] involved trigeminal nerves, 3 cases $[9,10,15]$ involved oculomotor nerves, and 7 cases [7, 12, 14, 17, 19, 21, 23] involved vestibulocochlear and facial nerves. Headaches were 


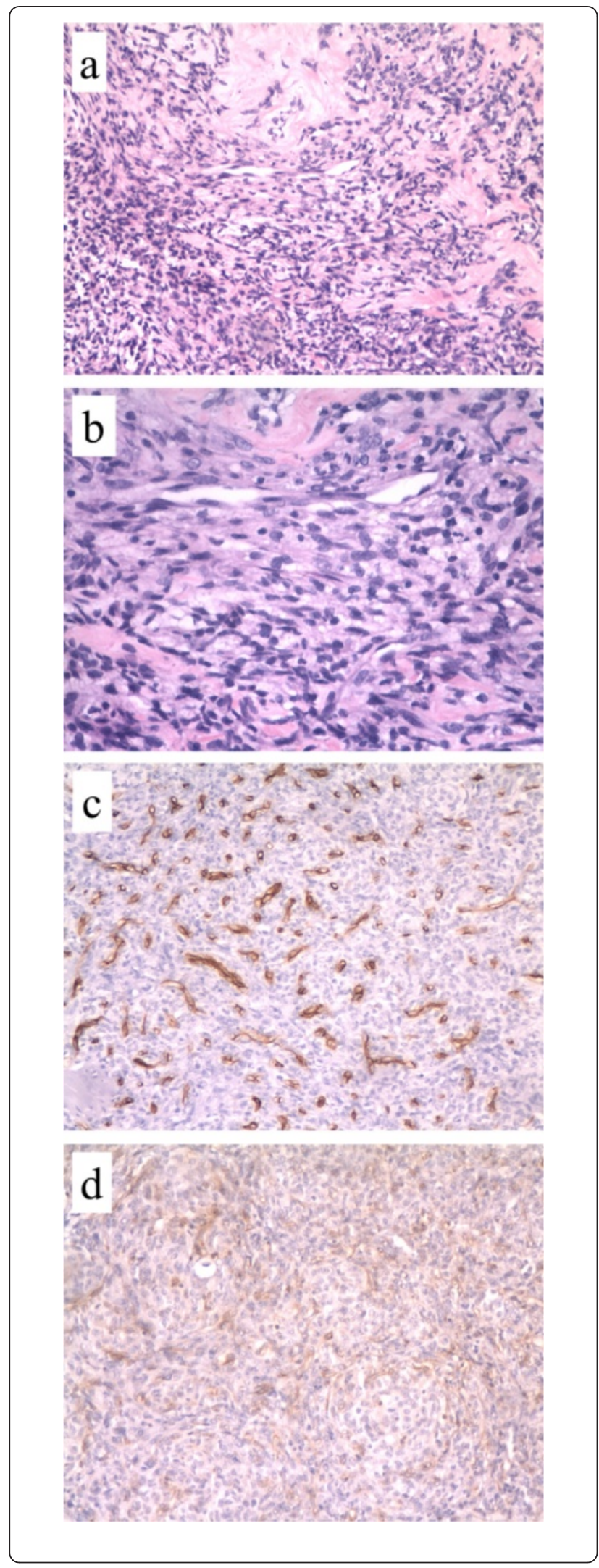

Fig. 4 Histopathologic images. a, b Histological images revealed a cellular schwannoma (original magnification, $\times 100$ and $\times 200$ ). a $(\times 100)$ The cells were densely distributed in most of the regions under low magnification. Hyalinized blood vessels can be visible. b $(\times 200)$ In the densely cellular areas, the nuclei were elongated and the cell boundary is not clear, nuclear chromatin increased, nuclei had moderate atypia, but mitotic activity is low, <4/10 HPF. c Immunohistochemical staining for CD34 was negative (not consistent with hemangiopericytoma; original magnification, $\times 200$ ). d Diffuse strong positivity staining for S-100 protein (original magnification, $\times 200$ )

present in 11 cases. Hydrocephalus was present in 4 cases $[4,5,7,12]$. About the present patient, 3 preoperative pictures at 10,12 , and 14 years old descript the symptoms and course of the 6th nerve palsy accurately.

\section{Diagnosis}

Almost all cases of abducens nerve schwannoma were misdiagnosed preoperatively. It is high possibility that the tumors were initially misdiagnosed as trigeminal or vestibular schwannomas. The trigeminal schwannomas could show isolated 6th nerve palsy, and the 6th nerve schwannoma could present without any 6th nerve palsy. In addition, the low incidence is the significant cause for most surgeons. The location and the attachment to the 6 th nerve is the key for diagnosis. Some cases $[5,7,10,11]$ were not revealed during surgery that it comes from the 6th nerve. Therefore, the 6th nerve schwannoma diagnosis could only come from the pre- and postoperative neurological deficit. In the present case, the definite diagnosis of the 6th nerve schwannoma was established from intraoperative observation of the tumor location and the attachment to the 6th nerve, as well as from the neuroimaging and the obvious isolated 6th nerve palsy preand postoperatively. It should be emphasized that ampliative Dorello's canal demonstrated the tumor origination from the 6th nerve, for only the 6th nerve enters the cavernous sinus through Dorello's canal, which is located between the petrosphenoidal ligament and petrous apex.

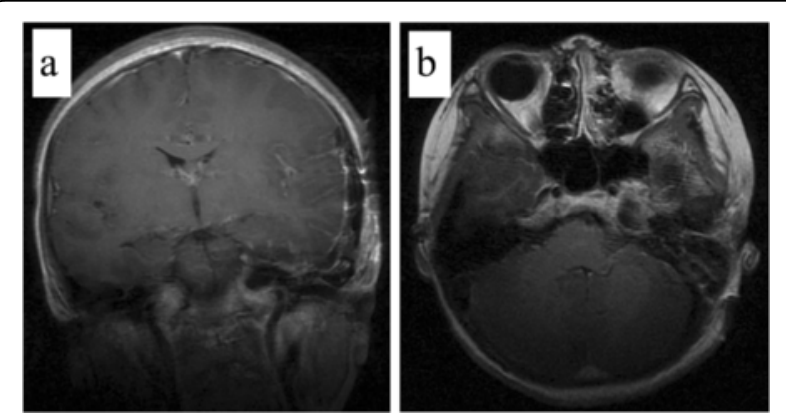

Fig. 5 Postoperative MRI findings. a, b Coronal and axial T1-weighted MRI done 6 days postoperatively showed decompression and revealed no residual tumor growth at the pons 
Table 1 Cases of intracranial 6th nerve schwannomas published in the literature

\begin{tabular}{|c|c|c|c|c|c|c|c|c|c|}
\hline No. & Reference & Age & Sex & Symptoms & Location & Consistency & Approach & Removal & VI recovery \\
\hline 1 & Chen [4] & 46 & $\mathrm{~F}$ & 6th, headache & $\mathrm{Cl}$ & Solid & Suboccipital & Total & Partial \\
\hline 2 & Leunda et al. [5] & 10 & M & 5th, 6th, headache & $\mathrm{Cl}-\mathrm{CA}$ & Solid & Subtemporal & Total & Paresis \\
\hline 3 & Hansman et al. [6] & 58 & M & 6th & $\mathrm{Cl}-\mathrm{CA}$ & Solid & $?$ & Partial & Paresis \\
\hline 4 & Ginsberg et al. [7] & 47 & $\mathrm{~F}$ & 5th, 6th, 7th headache, vertigo & $\mathrm{Cl}-\mathrm{CA}$ & Cystic & $?$ & $?$ & $?$ \\
\hline 5 & Tung et al. [8] & 35 & M & 6th & $\mathrm{Cl}-\mathrm{CA}$ & Cystic & Frontotemporal & Total & Paresis \\
\hline 6 & Tung et al. [8] & 45 & $\mathrm{~F}$ & 6 th & $\mathrm{Cl}-\mathrm{CA}$ & Mixed & Frontotemporal & Subtotal & Paresis \\
\hline 7 & Barat et al. [9] & 49 & $\mathrm{~F}$ & 3 rd, 5th, 6th & CA & Cystic & Frontotemporal & Subtotal & Paresis \\
\hline 8 & Lanotte et al. [10] & 62 & M & 3rd, 5th, 6th headache & CA & Solid & Frontotemporal & Total & Paresis \\
\hline 9 & Okada et al. [11] & 54 & $\mathrm{~F}$ & 5th, 6th, headache & $\mathrm{Cl}$ & Mixed & Transcondylar & Subtotal & Paresis \\
\hline 10 & Beppu et al. [12] & 66 & M & $\begin{array}{l}\text { 5th, } 6 \text { th, tinnitus, vertigo, } \\
\text { hypoacusis }\end{array}$ & $\mathrm{Cl}$ & Solid & Suboccipital lateral & Partial & Paresis \\
\hline 11 & Ichimi et al. [13] & 61 & $\mathrm{~F}$ & 5th, 6th & $\mathrm{Cl}$ & Cystic & Suboccipital lateral & Total & Paresis \\
\hline 12 & Suetake et al. [14] & 31 & $\mathrm{~F}$ & 5th, 6th, hypoacusis & $\mathrm{Cl}$ & Cystic & Suboccipital lateral & Subtotal & Partial \\
\hline 13 & Lo et al. [15] & 19 & M & $3 \mathrm{rd}, 6 \mathrm{th}$, headache & CA & Solid & Subtemporal & Subtotal & Paresis \\
\hline 14 & Acharya et al. [16] & 40 & $\mathrm{~F}$ & 6th & $\mathrm{Cl}-\mathrm{CA}$ & Solid & Subtemporal & Subtotal & Paresis \\
\hline 15 & Nakamura et al. [17] & 42 & M & Headache, vertigo, hypoacusis & $\mathrm{Cl}$ & Solid & Suboccipital & Total & Complete \\
\hline 16 & Nakagawa et al. [18] & 47 & $\mathrm{~F}$ & 5 th, 6th & CA & Solid & $\begin{array}{l}\text { Anterior } \\
\text { transpetrosal }\end{array}$ & Total & Complete \\
\hline 17 & $\begin{array}{l}\text { Mascarenhas et al. } \\
\text { [19] }\end{array}$ & 39 & $\mathrm{~F}$ & 6th, headache, exophthalmos & CA & Cystic & Orbitozygomatic & Subtotal & Paresis \\
\hline 18 & Erlich et al. [20] & 26 & $\mathrm{~F}$ & 6th, headache & $\mathrm{Cl}-\mathrm{CA}$ & Mixed & Suboccipital & Subtotal & Paresis \\
\hline 19 & $\begin{array}{l}\text { Vachata and Sames } \\
{[21]}\end{array}$ & 60 & M & $\begin{array}{l}\text { Hypoacusis vertigo, headache, } \\
\text { falls }\end{array}$ & $\mathrm{Cl}$ & Cystic & $\begin{array}{l}\text { Anterior } \\
\text { transpetrosal }\end{array}$ & Total & Complete \\
\hline 20 & Park et al. [22] & 36 & M & 6th & $\mathrm{Cl}-\mathrm{CA}$ & Cystic & Suboccipital & Total & $\begin{array}{l}\text { Complete } \\
\text { (anastomosis) }\end{array}$ \\
\hline 21 & Wang et al. [23] & 68 & M & Vertigo, headache & $\mathrm{Cl}-\mathrm{CA}$ & Solid & Suboccipital & Total & Partial \\
\hline 22 & Present case & 14 & $\mathrm{~F}$ & 6 th & $\mathrm{Cl}$ & Solid & Subtemporal & Subtotal & Paresis \\
\hline
\end{tabular}

$\mathrm{F}$ female, $\mathrm{M}$ male, $\mathrm{Cl}$ cisternal type, $\mathrm{CA}$ cavernous type, $\mathrm{Cl}-\mathrm{CA}$ cisternocavernous type, 3rd oculomotor nerve, 4 th trochlear nerve, 5th trigeminal nerve, 6 th abducens nerve, 7 th facial nerve, ? Not described in the literature

Histological images of our case revealed a cellular schwannoma with spindle cells in a collagenous background (Fig. 4a, b). Cellular schwannomas are a variant of standard schwannomas. They show a benign clinical behavior relative to standard schwannomas, but they are more likely to local recurrence [2].

\section{Operation}

Based on the location of the tumor, most cases are treated by a suboccipital $[4,12-14,17,20,22,23]$ approach, then subtemporal $[5,15,16]$ (present case) and frontotemporal [8-10] approaches, and anterior transpetrosal [18, 21], orbitozygomatic [19], and transcondylar [11] approaches for a few patients. Schwannomas located partially or entirely in the cavernous sinus are a completely special surgical group. Frontotemporal [8-10] or subtemporal $[5,15]$ approaches or their variations [18] are used. One-half cases of the CI types and one-half cases of the CI-CA type schwannomas obtain a radical resection, respectively. Tumor residue was left on the brainstem [5] (present case) or the 6th nerve [13]. In our present case, the tumor was adherent to the prepontine cisternal part of the pons and the basilar artery. Comparatively speaking, 2 $[10,18]$ out of 5 cases belonging to CA types obtain total resection (Table 2). Most of this type was not totally removed because of invasion of the cavernous sinus or firm adherence to the nerves.

Because of the frangible nature, the 6th nerve function seldom completely recovered postoperatively. A complete recovery was obtained in only 4 cases $[17,18,21,22]$. The case of CA type presented by Nakagawa [18] is out of the

Table 2 Result of resection of the 6th schwannoma in different locations

\begin{tabular}{llll}
\hline Type & Total & Subtotal & Partial \\
\hline Cl & 4 & 3 & 1 \\
CI-CA & 4 & 3 & 1 \\
CA & 2 & 3 & \\
\hline
\end{tabular}

The first horizontal line displays the extent of resection $\mathrm{Cl}$ cisternal type, $\mathrm{CA}$ cavernous type, $\mathrm{Cl}-\mathrm{CA}$ cisternocavernous type 
ordinary. It showed transient diplopia preoperatively and complete recovery of the 6th nerve function postoperatively. Reference [22] is the second case whom there was diplopia preoperatively and complete postoperative recovery of the 6th nerve palsy. The tumor was cystic and located in the CI-CA. An anastomosis was performed following total resection of the tumor. The other two cases reported by Nakamura [17] and Vachata and Sames [21] are both belonging to CI type and showed no diplopia preoperatively and complete recovery of the 6th nerve function postoperatively. These may be due to tumor growth that has been functionally compensated by the rest of intact nerve fibers. Above all, it seems easier to recover the function of the 6th nerve in cases of schwannomas in the CI-type group. The prognosis for the 6th nerve function was not in a good status in the present case, perhaps because the tumor had invaded into the cavernous sinus through Dorello's canal and was adherent to the 6th nerve, the pons, and the basilar artery.

\section{Stereotactic radiosurgery}

Regarding an alternative or adjuvant therapy, stereotactic radiosurgery has been reported [26, 27] for controlling nonvestibular schwannomas. In 2010, Hayashi et al. [24] performed stereotactic radiosurgery in 4 intracavernous 6th nerve schwannomas. The tumors are small in size and controlled to grow without acute complications or adverse effect. It could be an alternative measure for a small one. All in all, the direction of further research is to improve the diagnosis and therapy for the 6th schwannomas to have better postoperative recovery.

\section{Conclusion}

This is a case of a 14-year-old girl with a CI type of 6th schwannoma. 3 preoperative pictures at 10,12 , and 14 years old descript the symptoms and course of the 6th nerve palsy accurately. Subtotal removal of the tumor was performed. The attachment to the 6th nerve was found. The ampliative Dorello's canal demonstrated the tumor origination from the 6th nerve. Histological images revealed a cellular schwannoma. Till date, 22 cases of intracranial schwannomas of the 6th cranial nerve pathologically confirmed were reported, the classification, clinical presentation, diagnosis, operation, stereotactic radiosurgery are reviewed in detail. The location and the attachment to the 6th nerve is the key for diagnosis. Most cases are treated surgically. It looks like it is not easy to completely remove for CA type because of invasion of the cavernous sinus or firm adherence to the nerves. The 6th nerve function seldom completely recovered postoperatively. The direction of further research is to improve the diagnosis and therapy to have better nerve recovery.

\section{Consent}

Written informed consent was obtained from the patient for publication of this case report and any accompanying images. A copy of the written consent is available for review by the Editor-in-Chief of this journal.

\section{Competing interests}

The authors declare that they have no competing interests.

\section{Authors' contributions}

The authors' contributions to the study and manuscript preparation include the following. $Z \mathrm{~W}, \mathrm{XL}$, and $\mathrm{J}$ carried out the neurosurgery and obtained the specimen. $\mathrm{XL}$ collected the data of the patient and drafted the manuscript. JjL carried out the pathology and immunohistochemistry. JL helped to draft the manuscript. All authors read and approved the final manuscript.

\section{Author details}

${ }^{1}$ Department of Neurosurgery, Beijing Tian Tan Hospital, Capital Medical University, China National Clinical Research Center for Neurological Diseases, Center of Brain Tumor, Beijing Institute for Brain Disorders, Beijing Key Laboratory of Brain Tumor, Beijing, China. ${ }^{2}$ Department of Neuropathology, Beijing Neurosurgical Institute, Capital Medical University, China National Clinical Research Center for Neurological Diseases, Center of Brain Tumor, Beijing Institute for Brain Disorders, Beijing Key Laboratory of Brain Tumor, Beijing, China. ${ }^{3}$ Operating Department, Beijing Tian Tan Hospital, Capital Medical University, China National Clinical Research Center for Neurological Diseases, Center of Brain Tumor, Beijing Institute for Brain Disorders, Beijing Key Laboratory of Brain Tumor, Beijing, China.

Received: 16 April 2015 Accepted: 15 June 2015

Published online: 18 October 2015

\section{References}

1. Russell DS. Pathology of tumours of the nervous system. Baltimore: Williams \& Wilkins; 1989 .

2. Casadei GP, Scheithauer BW, Hirose T, Manfrini M, Van Houton C, Wood MB. Cellular schwannoma. A clinicopathologic, DNA flow cytometric, and proliferation marker study of 70 patients. Cancer. 1995;75:1109-19.

3. Louis DN, Ohgaki H, Weistler OD. WHO classification of tumours of the central nervous system. 4th ed. Lyon: IARC Press; 2007. p. 152.

4. Chen BH. Neurinoma of the abducens nerve. Neurosurgery. 1981;9:64-6.

5. Leunda G, Vaquero J, Cabezudo J, Garcia-Uria J, Bravo G. Schwannoma of the oculomotor nerves. Report of four cases. J Neurosurg. 1982:57:563-5.

6. Hansman ML, Hoover ED, Peyster RG. Sixth nerve neuroma in the cavernous sinus: CT features. J Comput Assist Tomogr. 1986;10:1030-2.

7. Ginsberg F, Peyster RG, Rose WS, Drapkin AJ. Sixth nerve schwannoma: MR and CT demonstration. J Comput Assist Tomogr. 1988;12:482-4.

8. Tung $\mathrm{H}$, Chen $\mathrm{T}$, Weiss $\mathrm{MH}$. Sixth nerve schwannomas. Report of two cases. J Neurosurg. 1991;75:638-41.

9. Barat JLMJC, Bracard SAJ, Martin-Beuzart SHH. Neurinomes des nerfs oculomoteurs. A propos de deux observations. Neurochirurgie. 1992;38:183-7.

10. Lanotte M, Giordana MT, Forni C, Pagni CA. Schwannoma of the cavernous sinus. Case report and review of the literature. J Neurosurg Sci. 1992;36:233-8.

11. Okada Y, Shima T, Nishida M, Okita S. Large sixth nerve neuroma involving the prepontine region: case report. Neurosurgery. 1997;40:608-10.

12. Beppu T, Yoshida Y, Wada T, Arai H, Suzuki M, Kuroda K, et al. Trochlear and abducens nerve neurinomas accompanied by a cerebellopontine angle meningioma_case report. Neurol Med Chir (Tokyo). 1997:37:416-21.

13. Ichimi K, Yoshida J, Inao S, Wakabayashi T. Abducens nerve neurinoma-case report. Neurol Med Chir (Tokyo). 1997;37:197-200.

14. Suetake $K$, Kurokawa $Y$, Uede $T$, Momota $H$, Hashi K. A case of abducens neurinoma mimicking acoustic neurinoma. Comput Med Imaging Graph. 1998:22:257-61.

15. Lo PA, Harper CG, Besser M. Intracavernous schwannoma of the abducens nerve: a review of the clinical features, radiology and pathology of an unusual case. J Clin Neurosci. 2001;8:357-60.

16. Acharya R, Husain S, Chhabra SS, Patir R, Bhalla S, Seghal AD. Sixth nerve schwannoma: a case report with literature review. Neurol Sci. 2003;24:74-9. 
17. Nakamura M, Carvalho GA, Samii M. Abducens nerve schwannoma: a case report and review of the literature. Surg Neurol. 2002;57:183-8. discussion 188-9.

18. Nakagawa T, Uchida K, Ozveren MF, Kawase T. Abducens schwannoma inside the cavernous sinus proper: case report. Surg Neurol. 2004;61:559-63. discussion 563

19. Mascarenhas L, Magalhaes Z, Honavar M, Romao H, Resende M, Resende PJ, et al. Schwannoma of the abducens nerve in the cavernous sinus. Acta Neurochir (Wien). 2004;146:389-92. discussion 391-2.

20. Erlich SA, Tymianski M, Kiehl TR. Cellular schwannoma of the abducens nerve: case report and review of the literature. Clin Neurol Neurosurg. 2009;111:467-71.

21. Vachata P, Sames M. Abducens nerve schwannoma mimicking intrinsic brainstem tumor. Acta Neurochir (Wien). 2009;151:1281-7.

22. Park JH, Cho YH, Kim JH, Lee JK, Kim CJ. Abducens nerve schwannoma: case report and review of the literature. Neurosurg Rev. 2009;32:375-8. discussion 378.

23. Wang $M$, Huang $H$, Zhou $Y$. Abducens nerve schwannoma in cerebellopontine angle mimicking acoustic neuroma. J Craniofac Surg. 2015;26:589-92.

24. Hayashi M, Chernov M, Tamura N, Yomo S, Ochiai T, Nagai M, et al. Gamma Knife surgery for abducent nerve schwannoma. Report of 4 cases. J Neurosurg. 2010;113(Suppl):136-43.

25. Celli P, Ferrante L, Acqui M, Mastronardi L, Fortuna A, Palma L. Neurinoma of the third, fourth, and sixth cranial nerves: a survey and report of a new fourth nerve case. Surg Neurol. 1992;38:216-24.

26. Nettel B, Niranjan A, Martin JJ, Koebbe CJ, Kondziolka D, Flickinger JC, et al. Gamma knife radiosurgery for trigeminal schwannomas. Surg Neurol. 2004;62:435-44. discussion 444-6.

27. Pollock BE, Foote RL, Stafford SL. Stereotactic radiosurgery: the preferred management for patients with nonvestibular schwannomas. Int J Radiat Oncol Biol Phys. 2002;52:1002-7.

\section{Submit your manuscript to a SpringerOpen ${ }^{\circ}$ journal and benefit from:}

- Convenient online submission

- Rigorous peer review

- Immediate publication on acceptance

- Open access: articles freely available online

- High visibility within the field

- Retaining the copyright to your article 